\title{
FORWARD-ORIENTED DESIGNING FOR LEARNING AS A MEANS TO ACHIEVE EDUCATIONAL QUALITY
}

\section{Patrizia M.M. Ghislandi, Juliana E. Raffaghelli}

\begin{abstract}
In this paper, we reflect on how Design for Learning can create the basis for a culture of educational quality. We explore the process of Design for Learning within a blended, undergraduate university course through a teacher-led inquiry approach, aiming at showing the connections between the process of Design for Learning and academic staff/student reflections on educational quality. As emerges from the evidence collected, forward-oriented design which is Design for Learning as iterative and participatory practice (Dimitriadis \& Goodyear, 2013) - supports meta-learning on the practices and values of educational quality. We introduce in depth the two main constructs adopted in our work - Design for Learning and educational quality - in order to understand the ongoing debate in these two separate (but convergent) areas of research. The four phases (design for configuration, design for orchestration, design for reflection, design for re-design) show the impact of design on educational quality reflections and practices. Alongside the process of Design for Learning, the data is collected and analyzed adopting different methods that enable the researchers to better understand the diverse perspectives of staff and students.

We conclude that Design for Learning can be deemed a mediational instrument to explore methods of transforming existing educational situations into desired situations, linking the vision of educational quality with concrete practices of the teacher and students' daily activities.
\end{abstract}

Keywords: Design for Learning; networked learning; higher education quality; quality literacy; teacher-led inquiry 


\section{Practitioner Notes}

What is already known about this topic

- Design for Learning is an emerging field of educational research and practice.

- A primary focus of Design for Learning is understanding how intuitive processes undertaken by teachers and trainers can become visible (Design for Learning as representation).

- A more recent focus is how pedagogical practices can be re-shaped in light of Design for Learning as iterative and participatory practice (Design for Learning as forward-oriented device).

- Empirical research is required to understand how Design for Learning can be connected to effective teaching and learning practices

\section{What this paper adds}

- Design for Learning enacts metacognitive processes connected to the analysis of teaching/learning theory and practices by both teaching staff and students. This is a process that mediates the achievement of the participants' educational quality literacy, a step towards a quality culture, and finally to progressive educational quality implementation.

- Design for Learning can be deemed to be a mediational instrument to explore methods of transforming existing educational situations into desired situations, linking the vision of educational quality with concrete practices of the teacher and students daily activities.

- Teacher-led inquiry can be used as a research methodology to explore the connections between Design for Learning (as a dynamic, forward-oriented device) and Educational Quality.

\section{Implications for practice and/or policy}

- Further empirical research is necessary to clarify how Design for Learning can concretely influence teaching and learning practices. In this paper, we analyze the relationship between Design for Learning and quality in Higher Education.From the practitioners' point of view (frequently the teaching staff), we demonstrate that sharing with students the quality principles governing higher education can have positive impact on understanding, negotiating and innovating for educational quality. Opening Design for Learning to the students is a way to share quality principles.

- From the political point of view, we see the need to devote time and resources to staff development in Higher Education on Design for Learning as an instrument to implement educational quality. 


\section{Introduction}

The ongoing debate about Learning Design as a key field of educational research and practice is focused on understanding how intuitive processes undertaken by teachers and trainers can become visible. Following this vein there has been, in recent years, considerable attention devoted to developing sophisticated Learning Design representational tools. The problem is nowadays whether these tools can be adopted into the daily practice of teaching and learning and connected to educational quality (effective teaching and learning according to negotiated educational values). In the following section we analyze Learning Design as an emerging field of research; we reflect on educational quality as a mediated process, and present our theoretical position about using Learning Design to attain educational mediated quality. Our position is then supported by an empirical study based on a teacher-led inquiry methodology.

\section{Learning Design: an emerging strand of educational research}

Learning Design can be considered a recent branch of educational sciences that is evolving rapidly. Its aim is to provide educators with specific tools and concepts to explore educational problems and make more grounded decisions to plan/implement their pedagogical practices (Conole, 2012a). The term Learning Design was coined to replace "Instructional Design", which was based on learning theories like behaviourism and cognitivism (Gustafson, Branch \& Maribe, 2002; Reiser, 2000). The Learning Design (LD) movement started at the end of the 1990s and attempted to go a step beyond the Instructional Design concept, taking into account the open-ended, loosely-defined nature of educational interventions based on socioconstructivist approaches mediated by technologies (Mor \& Craft, 2012).

The focus of the LD movement has been mostly in the direction of improving the status of teaching (within educational sciences) as design science (Laurillard, 2012), based on designerly ways of knowing (Cross, 2007), a different epistemogical approach in comparison with those of the natural sciences and the humanities. The scientific debate has centred the problem of representing learning and teaching strategies as a means to promote effective reflection and sharing of practices (Conole, 2010, 2012; Koper, 2006). Moreover, the LD movement claims that a clearer representation of envisaged pedagogical practices could have an impact on further sharing, discussing, and opening up the educational processes. The research in the field has shown that LD representational tools allow trainers other than the original "creator" of an educational intervention to discuss, remix, and recreate educational processes; it has also been argued that LD representations improve learners' understanding of the activity framework in which they are engaged (Mor, Craft \& Hernández-Leo, 2013; Persico, 2013). Regarding this position, some designs could be more connected to the visual representation of ideas (Agostinho, Harper, Oliver, Hedberg, \& Wills, 2008; Botturi, 2006), while others would search for patterns and templates that allow educators to develop their own ideas supported by the inputs given by the schemes for design (Goodyear, 2005; Mor \& Craft, 2012). Educational Technologies (Learning Management Systems -LMS-, social networks, web 2.0 and mobile applets) have provided a base to track and visualize learning processes and outcomes. Therefore, they have been also adopted to support Learning Design (Conole, 2012).

In the last two years new concerns about the use of Learning Design have been raised. In particular, there has been criticism regarding the idea of merely representing and expecting impacts of this activity on educational effectiveness and outcomes (Agostinho, 2011). As Persico and Pozzi (2013) point out, schemes and graphic representations are not new practices in the field of Learning Design . The authors go further to say that from the ' $80 \mathrm{~s}$, for example, 
conceptual maps have been used to describe and govern an educational intervention's complexity (op. cit., p. 137). This complexity requires flexible and intuitive tools that can be easily adjusted alongside with the implementation of educational activities, having as impact a teacher's reflection and improvement of professional practice.

In a recent article, Goodyear and Dimitriadis (2013) emphasize the need to connect LD activities with pedagogical practices in the green field - the field of the teacher and students' daily activities - through an iterative process where representations are used and reconstructed against real practices. For these authors, the LD representations must be used and re-structured by teaching staff alongside the implementation of educational initiatives. The authors then propose to move from the concept of "LD" towards the concept of Design for Learning. While LD as representation would reinforce the idea of an a priori, static object regarding established standards of quality, Design for Learning, as a forward-oriented practice, is linked to a dynamic process. This is in line with Wenger, who states that, "Learning cannot be designed: it can only be designed for - that is facilitated or frustrated" (Wenger, 1998, p. 229). We built on these notions to propose the adoption of Design for Learning as a means of achieving teaching/learning quality. In fact, Design for Learning aligns with a conception of quality as a participatory and progressive process of negotiation of values and practices in an educational setting.

\section{Educational quality culture: the mediated approach}

We consider now the debate on quality in higher education in order to understand the connections we will attempt to make between Design for Learning and educational quality. The conceptions of quality in higher education are today moving from quality assurance - an analysis focused on the products (the lesson, an educational resource, a learning environment) delivered from a producer to a consumer, where universal top-down criteria ensure the quality of a certain product - to an approach where reflection about quality and the connected improvements on practices are important conditions to align individual identities and organisational cultures to build contextualized quality cultures (Ehlers \& Schneckenberg, 2010). In line with this, the trends of research in the European Framework for Quality eLearning (EFQUEL) (Ehlers, Helmstedt, \& Bijnens, 2011; European Foundation for the Quality of eLearning, 2006) emphasise the notion of quality as a participatory process where the learners/users' visions are fundamental. This debate was based on explorations about the concept of quality that led to the conclusion that quality in education should be considered a multiperspective, multilevel, and contextualised process (Auvinen \& Ehlers, 2007; Ghislandi, Pedroni, Pellegrini \& Franceschini, 2008). The challenge is how to promote engagement and acknowledgement of diverse perspectives alongside the process of participation. Only in this way can tensions and contradictions among the several stakeholders' values regarding quality be overcome (Ghislandi \& Raffaghelli, 2012). As Ehlers puts it: "Quality strategies... cannot mechanistically guarantee high quality of learning processes but should aim rather at professionalization of the pedagogical process - for both clients and providers" (Ehlers, 2007, p.97).

Quality is based on stakeholders' skills in understanding the educational context, to negotiate their perspectives, and to analyse the results of their own practices in the light of shared values. According to Ehlers' model of quality culture, the educational quality has to be considered a 
strategy oriented to continuing improvement of processes and results (Ehlers, 2009). Quality culture is based on four elements, namely:

1. A structural element (the visible quality system of an organisation).

2. Enabling factors (the tools/engines that allow the implementation of quality systems).

3. Quality culture (the values, symbols, heroes, and rituals linked to the idea of quality).

4. Transversal elements (the forms of participation, communication, and trust that maintain a certain quality approach).

A quality culture cannot be changed/improved if stakeholders are not aware of these elements, at least partially. Ehlers further emphasizes that quality systems implemented as exogenous (mostly based on structural elements) tend to conflict with organizational culture and hence tend to be applied superficially. Instead, endogenous quality systems take into consideration actors' participation, engagement, and awareness about the quality system governing processes and production. This form of stakeholders' information, skills, and ability to transfer into practice the quality values is called by the author quality literacy — a concept that is promoted by four important dimensions (Ehlers, 2007):

1. Quality knowledge (to know what about quality).

2. Quality experience (to have the necessary instruments to implement quality).

3. Quality analysis (to evaluate, and understand the evaluation, of quality).

4. Quality innovation (to modify actively what is necessary to promote better quality).

How can stakeholders (like students and teaching staff) improve their educational quality literacy? We have emphasised the idea of stakeholders' co-responsibility and motivation to participate in the quality approach as a process of meta-learning. Grounded in the sociocultural perspective initiated by Lev Vygotskij $(1962,1978)$, we elaborated the concept of mediated quality, which is based on the introduction of mediating artefacts as well as a process of scaffolding to learn to participate in a quality culture (Ghislandi, Raffaghelli \& Yang, 2013). The result of this process is the achievement of quality literacy (as defined by Ehlers) among the participants. Operationally, the process of mediation for quality consists of:

1. Improving information about the quality system (Quality knowledge).

2. Learning to adopt/adapt instruments to achieve quality (Quality experience).

3. Self/peer evaluating processes and results according to the acknowledged principles of quality (Quality analysis).

4. Reflecting and adjusting such processes and results (Quality innovation).

We contend here that Design for Learning, as a forward-oriented process, can work as an instrument of mediation, enabling the negotiation of quality values attached to pedagogical practices and assumptions.

\section{Connecting the approach of mediated quality with Design for Learning.}

Having introduced our conception of mediated quality in educational interventions, let us now connect it to the process of Design for Learning. We found the basis for thinking about the connections between Design for Learning and educational quality in the seminal work of Simon (1969). As this author suggests, "everyone designs who devises courses of action aimed at changing existing situations into desired ones" (Simon, 1969 [1996], p. 129). In line with this, we can affirm that quality is a process in search of negotiation of human values within contextualised activities towards desired situations. As argued, Design for Learning can become an instrument of mediation, in the sense of a dynamic process that enacts participants 
to reflect about the values, processes and outcomes of an educational intervention. In this regard, we should reconsider the ongoing debate about the definition of Learning Design aiming at consolidating the concepts used in our research. Building on the theoretical contribution of Goodyear and Dimitriadis, Design for Learning within a quality culture should go beyond a deterministic conception of Learning Design as the ex-ante representation of a pedagogical intervention. In other words, Design for Learning should do more than provide initial, ab ovo representations or patterns explaining the teachers' and students activity within an educational intervention; instead, it should be considered as a continuing process of reframing practice, in medias res (op. cit., p. 3). As a result, Design for Learning would become a more forwardlooking process (op. cit.) that occurs at several stages of the educational intervention and influences it in an iterative process that includes:

a) Design for configuration, or the more traditional function of design, which has the purpose of representing and preparing the educational intervention.

b) Design for orchestration, which is the role of the represented pedagogical practice in supporting the implementation of the same.

c) Design for reflection, which is connected to the potential of a Learning Design to trigger reflection on the implemented pedagogical practices.

d) Design for redesign, which is the role of a represented pedagogical practice in supporting change and innovation applied to the implemented practice.

Moreover, Design for Learning as forward-looking process could influence the steps necessary to achieve quality, characterized as understanding and formulating principles of quality for learning; implementing them; analyzing their effectiveness; and formulating/representing systematically the innovations to adopt them in the future. As a participant-led process, Design for Learning implies a deep effort that may encompass significant changes in the professional values supporting practices, hence promoting the achievement of educational quality literacy, which is ultimately a step towards a quality culture, and to progressive educational quality implementation.

\section{The Study}

\section{Methodological approach: a teacher-led inquiry process of participatory design}

In our study, we attempted to demonstrate the connections between the process of participatory Design for Learning and educational quality. We further operationalized this relationship considering that Design for Learning is an instrument of mediation of quality, which has an impact on the achievement of quality literacy, or the reflection and skills to participate in a quality culture. Focusing our study in an online blended university course, our guiding research question was: Can the process of Design for Learning, intended as a participatory and iterative process, support the achievement of educational quality literacy? The methodological approach chosen was that of teacher-led inquiry. For this choice, we took into consideration the coherence between the ontology of the phenomenon analyzed (a transformational process) and the research goals (participatory Learning Design as a basis for the construction of a quality literacy) (Lincoln, Lynham, \& Guba, 2011). Teacher-led inquiry is an approach that relates Design for Learning, teaching as design science (Laurillard, 2012), and activities of inquiry where the same teacher/trainer/academic staff reflects on the effectiveness of innovations introduced as a result of the design (Kelly, 2003). Our approach encompasses teachers' engagement in the reflection and deep understanding of teaching and learning practices through Design-Based Research (DBR) activities.

DBR is a methodology developed mainly in the last ten years; it is based on educational design and implementation of experiments conducted in real classrooms (online or face-to-face) 
(Anderson \& Shattuck, 2012; Cobb, Confrey, diSessa, Lehrer, \& Schauble, 2003; Collins, Joseph, \& Bielaczyc, 2009; Gorard, Roberts, \& Taylor, 2004; Middleton, Gorard, Taylor, \& Bannan-Ritland, 2006; Mor \& Winters, 2007) While in traditional DBR the researcher conducts the experiments together with the teacher, in teacher-led inquiry the teacher is in fact the protagonist of a dynamic process of design research, consisting in setting the goals of a design experiment, planning and executing it, reflecting, and communicating the results of the whole inquiry (Dana \& Yendol-Hoppey, 2008). As Cobb et al. put it-"Design experiments - entail both 'engineering' particular forms of learning and systematically studying those forms of learning within the context defined by the means of supporting them. This designed context is subject to test and revision, and the successive iterations that result play a role similar to that of systematic variation in experiment". (Cobb et al., 2003; Brown, 1992; Gorard, Roberts \& Taylor, 2004)

Our design experiment encompasses a participatory process in the design of our blended course where we actively involve the main stakeholders: the teacher, teaching staff (designer and etutor), and students. It is also an iterative process, because the stakeholders' quality culture gained is a means to improve the educational quality of the next iterations of the course under analysis.

\section{The context of the inquiry}

We conducted the teacher-led inquiry over a period of three months (from September to December 2012) within the blended course IATI (Artificial Intelligence and Information Technologies, academic year 2012-2013, First Bologna Cycle of the career of Psychology at the University of Trento). The study was carried out in the context of a national research project in Italy (PRIN-Projects of National Relevance, Ministry of University, Education and Research of Italian Republic, .2009-) named Evaluation for the improvement of educational contexts: a research involving University and local communities in the participatory development of innovative assessment models with the cooperation of five Italian universities (Verona, Milan Catholic University of Sacred Heart, Trento, Milano-Bicocca, Pavia). The IATI course was undergoing its fourth edition and had been implemented through a collaborative approach. At the time of the intervention, it was dealing with issues raised by the students about the quality of the collaborative learning experiences. In fact, students had pointed out in the final quality evaluation the high workload in comparison with other courses, mainly based on traditional, face-to-face lessons. The challenge was therefore to engage students in a new quality perspective. Specifically, a design experiment was planned consisting of the implementation of a students' participatory evaluation for the selection of "quality learner generated content". The discussion between students and academic staff about the quality criteria should have led, in our vision, to the achievement of quality literacy by students.

\section{The field research activities}

The teacher-led inquiry process was hence based on the following field research activities:

a. Two preliminary design sessions between the academic teacher and the instructional designer.

b. Two academic staff sessions to monitor the progress of the design experiment.

c. One preliminary information and discussion session with two e-tutors (responsible for one of the course's modules and for the online forum).

d. Three observations in class. 
e. Continued monitoring of the online forum and direct interactions with students to address the experimental activity as well as to clarify questions regarding the procedures and strategies.

Academic staff comprised a university professor, an instructional designer (rather a designer for learning), and two eTutors. The professor was responsible for the changes applied to her own class and the whole process of re-design. The designer operated in the creative process by discussing and generating mediating artefacts, closely following students' concerns and requests during the implementation process of the participatory evaluation.

Hence, to understand our approach, we will introduce the above mentioned four components of the iterative design process (Dimitriadis \& Goodyear, 2013), analyzing the relationships and impact with the mediated quality approach. As outlined below, the LD tools and process should reflect the four moments of Dimitriadis and Goodyear's quality achievements, not only the configuration moment of LD. This last could be deemed the step of imagining and representing the strategy of change within IATI, and also the orchestration (as dynamic implementation), the reflection, and the further redesign for a future edition of IATI.

\section{The data analyzed}

A teacher-led inquiry produces heterogeneous sets of data that should be used to improve understanding, by the same teaching staff (or single teacher), of the phenomenon under analysis. DBR adopts a multiplicity of methods and the results must be handled by successive comparisons or triangulation, in search of convergence of several sets of data about a certain construct researched. In this regard, we collected qualitative sets of data (like design patterns and maps as the teaching staff's discourse and semiotics), as well as quantitative data coming from a survey of the students and data mining within the Learning Management System.

\section{The process of Design for Learning}

\section{Design for configuration}

The initial configuration phase was mainly based on facing the problem of introducing a vision of quality that would create better awareness among students about the benefits of a networked learning approach. The documented goals, as also expressed by the professor in an online forum, do not only regard the achievement of knowledge on the topic, but also the development of transversal competences crucial both for the students' future professional profile as well as for lifelong learning. The initial course, which had a workload of 8 European Credits Transfer System (ECTS), was divided into four main modules (see Table 1)

\section{Table 1. The four modules of the IATI course where the design experiment took place}

\section{$<$ Pls. Insert Table 1 $>$}

As emerges from Table 1, the most complex learning task regarded Module 2 (M2), where the students elaborate on concepts of Artificial Intelligence and generate classroom presentations followed by discussion. The pedagogical approach emphasises students' collaboration and engagement. In fact, while M0 and M1 are preparatory activities for a socio-constructivist approach as learning communities, and M3 is with traditional lectures and a final exam, M2 is the core of the course collaborative activity. As such, it was selected for the implementation of the new design element, a participatory evaluation of Learners Generated Content (LGC). 
The teaching staff started the design work about two months before implementation of the IATI course, adopting two simple but effective Learning Design tools: the Design narrative (Mor \& Noss, 2008; Mor, 2011) and force maps (Mor, Learning Design Grid Project, 2012). The goal was to discuss the quality problems and to introduce a design experiment that would lead to the achievement of quality literacy. The design narrative was considered appropriate because it did not imply the adoption of complex Design for Learning technologies, which are to some extent intrusive with the planning of pedagogical interventions. The design narrative was adopted for its "intuitive" potential (Mor, 2011). According to Mor: "The design narratives are accounts of critical events in a design experiment from a personal, phenomenographic perspective. They focus on design in the sense of problem solving, describing a problem in the chosen domain, the actions taken to resolve it and their unfolding effects. They provide an account of the history and evolution of a design over time, including the research context, the tools and activities designed, and the results of users' interactions with these. They portray the complete path leading to an educational innovation, not just its final form - including failed attempts and the modifications they espoused" (op. cit., p. 3).

Our design narrative was placed at the beginning of the design experiment and included the story of changes that the course IATI had undergone from its beginning. The initial decision had been, in fact, to integrate a networked learning approach in a context where eLearning was used to be implemented in more traditional ways.

As it was reflected in an excerpt of our Design Narrative,

"The networked learning approach should encompass the achievement of skills other than knowledge of Artificial Intelligence (AI) Basing on a socio-constructivist pedagogy, it should enable students to collaborate to build new knowledge that could be in time opened up to the next generation of students... The problem to be faced during the implementation has been not only the pedagogical traditions within the institution, but the students' conceptions of what is valuable for them; and this is, to achieve what they need to pass an exam... the collaborative approach every year yields enthusiastic participants, but it also generates complaints in reference to the workload. If the new design adopted a space for reflection on the quality of networked learning, enabling students' awareness of it, this would lead to better student engagement"

The second element used was that of force maps. Stemming from the narrative account of the situation to be changed, the academic staff attempted to draft the forces driving the success as well as risks of the Learning Design. In fact, a "Force Map is a graphical representation of the context of a design challenge. It includes iconic representations of the key elements in this context (social, material, and intentional factors) and lines noting the relationships between them. These relationships are marked "+" when supportive, and "-" when indicating a tension. The design challenge can often be defined in terms of resolving some of these tensions". (Mor, Learning Design Grid Project: Force Map, 2012) Figure 1 shows the force map created.

Figure 1. Force map representing the challenges addressed by the design experiment within IATI

\section{$<$ Pls. Insert Figure 1 $>$}

In this map the problem of introducing quality eLearning was considered as the challenge driving Design for Learning. The negative forces (attachment to tradition, naïf pedagogical knowledge, limited information technology skills) block the already existing positive forces: an academic community interested in developing networked learning as part of renewing pedagogy in higher education; support from educators with expert profiles in the area of 
eLearning; support from the growing interest in open content. Furthermore, the map shows specific positive forces that constitute a unique opportunity for change - that is, the interest and motivation of the students willing to collaborate in generating content, and embracing the idea of collaboration between academic staff and students for quality networked learning. Indeed, the force map helped the academic staff to visualize and focus this opportunity. As a result of the adoption of these two LD tools a new, experimental learning was considered: the participatory evaluation of learners' generated content as an activity supporting awareness of educational quality values. In this context participatory evaluation was deemed a process of learning itself in order to achieve quality literacy. There were mediating artefacts for this learning process that we describe in the following paragraphs.

\section{Design for Orchestration}

Table 2 introduces the process of participatory evaluation as a synthesis of the new LD, identifying the mediating artefacts and the dimensions of quality literacy supported by the activities.

Table 2. Participatory evaluation (design experiment) in IATI Module 2 as quality mediating process

\section{$<$ Pls. Insert Table 2>}

The students (n:171) were invited to take part in the participatory evaluation but were not obliged to follow the activities. These were presented during the first classroom lesson, explaining to the students in a short and simplified way the policy context, research background, goals, and characteristics of the activity. Specifically, the following issues were introduced: modality of participation (which was expected only on voluntary basis); data treatment (data gathered anonymously for questionnaires and anonymized for publication). Informed consent forms were distributed and signed by all students.

While Table 2 was the starting point during the process — in order to guide students and build on their requests for clarification about the participatory activity, which was rather new - two other tools connected to the design process were adopted: the students' guide "Who? What? When? How?" and the "socio-constructivist protocol". While the former established the operational process, yielding also changes "on request", the second was a crucial instrument to keep the academic staff focused on the key learning tasks alongside the intervention. Both represented "design thinking supports" in the sense that guiding learning activities were also the base to adjust what was unclear or what was misleading in the strategies (pedagogy) and the tactics (learning tasks).

\section{Design for Reflection}

Design for reflection was connected to understanding the impacts of the participatory evaluation as design experiment activity within the teacher-led inquiry process. The design experiment activity was conducted during the second, third, and fifth weeks of Module 2 (six weeks long). It consisted of the following steps:

1. Each group defined the quality criteria for the evaluation of the assignments as LGC (Week 2, W2).

2. Each group peer-evaluated the quality of three other groups' assignments as part of the process of participatory evaluation, applying the negotiated quality criteria (W3).

3. Each group raised some questions to discuss during the final classroom presentations of the assignments (W5). 
4. Based on the groups' peer-evaluation, three assignments were selected as the best LGC of the IATI13 course and presented by the teacher in the classroom and incorporated in the content of the IATI course in the next year.

Data analysis was based on the integration of qualitative and quantitative data relating to students' learning outcomes, collected along with the participatory evaluation, with the aim of reflecting on the effectiveness of the approach initially designed and updated through the "orchestration".

It was based on:

1. Students' level of participation

a) Number of students having participated voluntarily in the experimental activity: 74 out of the total number of students, 171.

b) Number of interactions (posts within a group discussion or thread) between the students during the three weeks of the participatory evaluation (design experiment activity). The interactions in the threads referring to the experimental activity were compared to the "normal" online interactions in the threads regarding the Module 2 content (about understanding the idea of five fundamental thinkers in the field of Artificial Intelligence). The data were collected through the eLearning platform, which showed the different types and periods of access, separated both by the single participant and by the group.

2. Students' impressions about their meta-learning as an outcome of the participatory evaluation, based on answers to direct questions after the third module of the IATI course.

\section{Students' level of participation}

Out of 171 students enrolled in the course, 18 never started the course and 79 participated as "free" students (did the examinations but did not follow the course schedule). Among the remaining "active" 13 groups for a total of 74 students, all took part in the design experiment. These active students immediately showed high levels of engagement and collaboration, as well as consistent patterns of participation (measured as number of interactions per week). The results introduced in Table 3 showed an increasing number of interactions, particularly during the weeks devoted to the design experiment activities; the content of interactions regarded negotiations of the meanings of quality for the LGC, supporting the process of "mediated negotiation of quality". It is noted that many interactions were lost, due to the fact that during the week of the evaluation itself (W3), 7 out of 13 groups preferred to interact face-to-face or via email to accomplish the evaluation process. This was because they considered their comments too private to be left on the Learning Management System. However, this fact showed the high ethical commitment of the students during the process of participatory evaluation.

Table 3. Level of students' participation during the design experiment

$$
<\text { Pls. Insert Table 3> }
$$

The results regarding the students' level of participation confirmed high levels of engagement and collaboration between students, as well as consistent patterns of participation every week (an average of 11.75 interactions per student per week during Module 2). However, it is noted that intensity of interactions grew in 10 out of 13 groups, with higher performance for the Asuro group happening during the weeks of mediated negotiation of quality (design experiment activity, W2, W3, W5). This intense participation supports the assumption that the students 
were highly motivated and engaged to participate in the quality culture beyond the specific content they should learn. To expand on these preliminary results regarding the level of interactions and engagement, we further considered the students' impressions about the impact of the experimental participatory evaluation. In fact, students' impressions should shed light on the process of cultivating quality literacy.

\section{Students' Impressions}

The students' impressions about the process of participatory evaluation were collected through a questionnaire after the conclusion of the experimental activity. Forty-one students (out of 74) replied to the questionnaire, which was administered in electronic form. Table 4 synthesizes the results obtained through the questionnaire. It is to be noted that the dimensions indicated in the table are in fact a "label" originated from the more discursive statements proposed to the students, in which they had to respond adopting a Likert scale of 4 points. The scale of 4 points was adopted in order to avoid the central tendency bias (or "end-aversion", (Curtis, Murphy, \& Shields, 2013, p.108), that is, the selection of the "neither agree or disagree" option. For example, "perceived participation" refers to the following statement: "My participation in the experience was active", and the students had to reply using the scale 1-4 expressing levels of disagreement/agreement with the statement. In addition, the researchers grouped the original dimensions according to the theoretical definitions of the Quality Literacy model (Ehlers, 2007) as follows:

a) Dimension 0 "Motivational base for engagement": Columns 1, 2, 3.

b) Dimension 1 "Knowledge": Column 4.

c) Dimension 2 "Experience": Columns 5, 6, 7.

d) Dimension 3 "Analysis": Column 8, 9.

e) Dimension 4 "Innovation": Column 10.

Table 4. The results of the questionnaire after the students' participatory evaluation (design experiment)

\section{$<$ Pls. Insert Table 4>}

The questionnaire yielded interesting results regarding the main assumptions driving the experience. Firstly, column 1 shows that the students' perceptions about engagement were consistent with the objective data collected within the platform (40 out of 41 totally or somewhat agree). Columns 2 and 3 show that the experience was generally well accepted, but in some cases "hard" to carry out; some further interviews showed some students" concern about the experience as a disturbance to the normal schedule of a third-year student. However, the specific information grouped by the dimensions of "quality literacy" (knowledge, experience, analysis, innovation) underline how important the impact was on the achievement of specific skills and knowledge supporting quality literacy. Regarding the first dimension of the Quality Literacy (Knowledge), the students indicated that the tools adopted were indeed a support to motivate and better understand the process of evaluating quality (Column 4). Similarly, the students generally found the process of experiencing participatory evaluation (second dimension, Experience) formative in terms of acquiring general skills like study skills (Column 5), problem solving, and the ability to negotiate and collaborate in a group (Column 7 ), as well as understanding the process of evaluation from the teacher's side, improving their skills to present/prepare assignments (Column 6). These general skills also referred to the impact of the experience beyond the frame of quality literacy, and were related to the 
importance of acquiring competences for lifelong learning. More important to our goals of engaging students as collaborators in the process of generating quality literacy is motivation and learning about quality, referred by the students (Columns 8,9) as part of the Analysis dimension. As declared by a number of students ( 25 out of 41$)$, they better understood the role that students could have in improving the quality of contents as part of a quality course, while the clarity of the tools provided to assess quality was more controversial ( 15 strongly agree and 24 agree), though still positive. As a result, regarding the last dimension of Innovation, students acknowledged the important role they are called to play, jointly with the teacher, in improving quality (21 totally agreed and 18 rather agreed). An issue that clearly reinforced the process of passing from being motivated and knowing about quality to become "innovators" of quality, as part of quality literacy, was the selection of the three best assignments, which will be integrated as course contents for the next run of IATI.

\section{Design for re-design: a crucial step of design for quality learning}

After reflection on the key results obtained, it was time for re-design. We considered three elements leading re-design to improve the quality of the course under analysis, having achieved quality literacy as shown during the reflection phase of design. The first element regards the evidence supporting that a participatory approach to evaluation can positively lead to impacts on general skills crucial not only to consume quality, but to feel like prosumers, active participants engaged in a quality culture. The second element regards the inherent complexity of a participatory approach to evaluation. This experience was intense and time consuming both for the teacher and for the students. It encompassed an authentic learning task within a socio-constructivist learning environment (Jonassen et al., 1999), going beyond the specific course's content, but reinforcing, to some extent, the relevance of collaboration in exploring indepth (as part of the quality approach) the same content and generating new content, produced by the students. Therefore, we concluded that re-design should encompass the simplification of the participatory evaluation in terms of tasks, without losing its key components, which were the authentic task and the enhancement of learners' collaboration. The third and last important element was the generation of content by the students which is being concretely integrated into the next run of IATI (academic year 2013-14). This element is the result of a first design iteration, leading to new (learner-generated) content, which is expected to have further impact on learners in the following iteration.

\section{Discussion}

The Design for Learning landscape is complex, based on its rapid evolution as a research field, but practices, tools, resources, and theoretical frameworks should be reconsidered carefully (Mor \& Craft, 2012; Persico \& Pozzi, 2013). In fact, several studies are focused on providing the technologies and tools to represent an ideal initial situation as a means to enact reflection and sharing of pedagogical practices (Conole, 2012). Instead, other studies are showing new trends for the debate on Design for Learning, attempting to understand the impact of design on key aspects of learning through progressive iterations (Agostinho, Bennett, Lockyer \& Harper, 2013). These studies are well beyond the idea of controlling a whole system of practices as was the basic assumption of the instructional design. They promote, instead, the concept of representing for understanding and sharing ill-defined problems, such as those at the base of educational interventions. In so doing, the Design for Learning could reinforce the idea of teaching as a design science. 
We claim that the research on Design for Learning could take a crucial step forward if connected to several other concepts within educational research, such as that of educational quality. In this regard, the key constructs of learning science should be selected and studied, taking into consideration the types of Design for Learning tools and processes implemented, as carried out in studies like Design for Learning and collaborative learning (Kali, Levin-Peled, \& Dori, 2009), teachers' professional skills for design (Agostinho, et al. , 2013), or in the analysis of educational quality (Oliver, Harper, Wills, Agostinho, \& Hedberg, 2013). Thus, we have tried to connect two theoretical constructs: Design for Learning and educational quality. We presented the analysis of the process of Design for Learning within a blended, undergraduate university course. The design was implemented through a teacher-led inquiry, which included a design experiment - the participatory evaluation of learners' generated content - as part of a process to improve the quality of the course over its several iterations. We checked to which extent Design for Learning enabled teacher and students to reflect on the achieved quality. Our leading research question was: Can the process of Design for Learning, intended as a participatory and iterative process, support the achievement of educational quality literacy?

As discussed above, our design experiment consisted of a participatory evaluation of LGC to open it up as part of future design iterations. However, the activity could not itself guarantee the achievement of quality literacy. This was assured instead by the whole iterative process of Design for Learning, which in our research was characterized as a) reflecting on the quality of prior IATI course editions; b) design new interventions and representing them through cognitive tools; c) using these cognitive tools through the participatory approach to enable orchestration and d) further redesign of the IATI course. Not only did the students re-negotiate their beliefs about quality, but the academic staff reflected on the process, languages, and tools towards transformation for quality. In this regard, Design for Learning was the base to mediate participants' quality literacy achievement. For the students this was linked to their specific knowledge and skills regarding the quality of the content generated in a broader context of quality for higher education. For the staff quality literacy was linked to a deep understanding of the whole process of Design for Learning.

\section{Conclusions and implications for future research}

Building on Ehlers's concept of quality literacy (Ehlers, 2007), we hypothesized that scaffolding stakeholders' knowledge, experience, analysis, and opportunity to innovate laid the basis for a quality culture; this was called the mediated quality. We also assumed that the efficacy of this last construct was linked to the participatory and iterative logic, based on successive negotiations of goals and values for daily practice and life in an organization and what has been done effectively to achieve these. We attempted to show that Design for Learning could be an instrument to support mediated quality, in the condition of going beyond the design definition as representational mean and becoming a dynamic source of reflection on pedagogical practices. These assumptions are complex, and generalizations are not easy. The teacher-led inquiry does not specifically pursue the goal of massive transferability of results. Instead, it contributes to the debate questioning actual concepts (in our case, Learning Design as mere representation) and putting into practice small design experiments to explore new concepts (in our case, forward-oriented Design for Learning). New design experiments in the same context of implementation of our study, as well as the replication of our approach, could shed new light on the concepts discussed. 
The availability of technological tools, as demonstrated in the adoption of educational technologies, does not mean immediate pedagogical innovation, effectiveness, or quality. It seems to us that within the emergent research theme of Design for Learning, a further effort must be made in the upcoming years to overcome the initial enthusiasm of representing pedagogical practices. On the one hand, the types of tools and representational means developed in the last decade should be analyzed empirically. On the other hand, the process of Design for Learning as a device of change/improvement or forward-oriented should be explored. In that direction, studies like small, contextualized teacher-led inquiry (like ours) as well as wider institutional and cross-case studies should be considered, leading to greater precision in terminology and tools proposed to the larger educational community beyond the circles of designers and researchers. It is also crucial to recall that the way constructs are defined drives the empirical research and the conclusions are to be discussed in light of those definitions. It could be argued that we did not check final learning effectiveness as is expected in some models analyzing educational quality, such as the case of the Sloan C framework (Moore, 2005). In our approach to educational quality, our focus has been on skills to participate in a quality culture — not the overall, actual quality of the IATI course - so Design for Learning had an impact at that level; its impact on other dimensions of quality is still to be explored.

Another important issue to consider is how to deal with the maze of data generated along the process of Design for Learning to better inform the teaching and learning process as well as to support a process of inquiry. We blended both qualitative and quantitative data in order to understand the impact of the interventions hypothesized, and to make adjustments from one phase to the following alongside the process of Design for Learning. In this sense, even if we could not use learning analytics in the present experience, we acknowledged their enormous potential as quantitative data available to teaching staff. Learning analytics research is based on the opportunity of access, provided by Learning Management Systems, to big sets of data generated by learners while participating in several activities. The intelligent aggregation of these data becomes a strong tool for purposes of analysis and decision-making regarding educational processes (Ferguson, 2012). According to Castro, Vellido, Nebot, \& Mugica (2007), data mining is being used in eLearning for diverse purposes such as assessing students' learning performance, providing feedback and adapting learning recommendations based on students' learning behaviours, and detecting a typical student's learning behaviours. In our research approach, we examined the students records of access to the online forum regarding the topics of the design experiment to analyze the frequency and density of participation as part of their engagement in the debate on quality. This is an activity that could be connected to data mining and could be enhanced in future research, expanding the type and quantity of data tracked in order to test and validate the effectiveness of adopting design for learning strategies.

Although limited in its scope and target, our study encompasses some implications both at the political and practitioners' level. From the political point of view, we see the need to devote time and resources to higher education teaching staff development to understand the how to implement an iterative process of Design for Learning for quality. This issue is also supported by recent EU recommendations (McAleese, 2013). From the practitioners' point of view (frequently the teaching staff), it is crucial to share with students the quality principles governing higher education. Opening Design for Learning to the students is a way to do so. This could work as a support for understanding, negotiation and innovation of quality principles, leading to continuing improvement of practice. This is a further reason to think of Design for Learning not as a static and closed representation, but as a dynamic and open process. 
The contribution of Design for Learning to key educational problems like quality can be only guessed today; however, growing interest in this field indicates that we will witness effective research outcomes in the near future. Our work has shed light on the idea that Design for Learning can effectively be connected to other educational goals, like achieving educational quality. Again, this is the first step in a long process, paved with insights and achievements, but also uncertainty. It comforts us that uncertainty should be the main motivation to proceed, as it was expressed by the Italian poet Dante: "Che, non men che saver, dubbiar m'aggrata" (Dante, Inferno XI, 93) (that is Our doubts are no less valuable than the indisputable knowledge).

\section{References}

Agostinho, S. (2011). The use of a visual learning design representation to support the design process of teaching in higher education. Australasian Journal of Educational Technology, 27(6), 961-978.

Agostinho, S., Bennett, S., Lockyer, L., \& Harper, H. (2013). The Future of Learning Design (p. 128). London: Routledge.

Agostinho, S., Bennett, S., Lockyer, L., Jones, J., \& Harper, B. (2013). Learning Design as Stimulus and Support for Teachers' Design Practices. In H. Beetham \& R. Sharpe (Eds.), Rethinking Pedagogy for the Digital Age, Designing for the 21st Century (2nd Editio.). London, UK: Routledge.

Agostinho, S., Harper, B., Oliver, R., Hedberg, J., \& Wills, S. (2008). A visual learning design representation to facilitate dissemination and reuse of innovative pedagogical strategies in university teaching. In L. Botturi \& T. Stubbs (Eds.), Handbook of visual languages for instructional design: Theories and practices (pp. 380-393). Hershey, PA: Information Science Reference (IGI Global).

Anderson, T., \& Shattuck, J. (2012). Design-Based Research: A Decade of Progress in Education Research? Educational Researcher, 41(1), 16-25. doi:10.3102/0013189X11428813

Auvinen, A., \& Ehlers, U.-D. (2007). Handbook of Quality Management of Peer Production (p. 83). Brussels.

Botturi, L. (2006). E2ML: A Visual Language for the Design of Instruction. Educational Technology Research and Development, 54(3), 265-293. doi:10.1007/s11423-006-8807-x

Castro, F., Vellido, A., Nebot, À., \& Mugica, F. (2007). Applying Data Mining Techniques to e-Learning Problems. In L. C. Jain, R. A. Tedman, \& D. K. Tedman (Eds.), Evolution of Teaching and Learning Paradigms in Intelligent Environment. (pp. 183-221). Berlin: Springer-Verlag.

Cobb, P., Confrey, J., diSessa, a., Lehrer, R., \& Schauble, L. (2003). Design Experiments in Educational Research. Educational Researcher, 32(1), 9-13. doi:10.3102/0013189X032001009

Collins, A., Joseph, D., \& Bielaczyc, K. (2009). Journal of the Learning Design Research : Theoretical and Methodological Issues Design Research : Theoretical and Methodological Issues, (September 2012), $37-$ 41.

Conole, G. (2010). Learning design - making practice explicit. In Proceedings of the 2nd International Conference on Design Education, ConnectEd 2010. Sydney, Australia.

Conole, G. (2012). Designing for Learning in an Open World.

Cross, N. (2007). Designerly Ways of Knowing (Google eBook) (p. 138). London: Springer-Verlag.

Curtis, W., Murphy, M., \& Shields, S. (2013). Research and Education (p. 240). New York, NY: Routledge.

Dana, N. F., \& Yendol-Hoppey, D. (2008). The Reflective Educator's Guide to Classroom Research: Learning to Teach and Teaching to Learn Through Practitioner Inquiry (p. 216). Corwin Press.

Laurillard, D. (2012). Teaching as a Design Science: Building Pedagogical Patterns for Learning and Technology. London: Routledge.

Dimitriadis, Y., \& Goodyear, P. (2013). Forward-oriented design for learning: illustrating the approach. Research in Learning Technology, 21. doi:10.3402/rlt.v21i0.20290 
EFQUEL European Foundation for the Quality of eLearning. (2006). Learners as active stakeholders of eLearning quality (pp. 1-5).

Ehlers, U.D. (2007). Quality Literacy - Competencies for Quality Development in Education and e-Learning. Educational Technology and Society, 10(2), 96-108.

Ehlers, U.D. (2009). Understanding quality culture. Quality Assurance in Education, 17(4), 343-363. doi:10.1108/09684880910992322

Ehlers, U.D., Helmstedt, C., \& Bijnens, M. (2011). Shared Evaluation of Quality in Technology-enhanced Learning. White Paper developed in the Framework of the SEVAQ+ Project, 25.

Ehlers, U.D., \& Schneckenberg, D. (2010). Changing Cultures in Higher Education: Moving Ahead to Future Learning (p. 568). Berlin: Springer.

Ferguson, R. (2012). Learning analytics: drivers, developments and challenges. International Journal of Technology Enhanced Learning, 4(5/6), 304-317.

Ghislandi, P., Pedroni, A., Pellegrini, A., \& Franceschini, D. (2008). eLearning e qualità. Il Giornale dell'eLearning, 2(3).

Ghislandi, P., \& Raffaghelli, J. E. (2012). Implementing Quality e-learning in Higher Education: change efforts, tensions and contradictions. In L. Gómez Chova, A. López Martínez, \& I. Candel Torres (Eds.), Proceedings of the Fifth Annual Edition of ICERI2012: 5th International Conference of Education, Research and Innovation (pp. 1107-1117). Barcelona, 19-21 November 2012: IATED. doi:ISBN 978-84616-0763-1

Ghislandi, P., Raffaghelli, J. E., \& Yang, N. (2013). Mediated Quality. International Journal of Digital Literacy and Digital Competence, 4(1), 56-73. doi:10.4018/jdldc.2013010106

Goodyear, P. (2005). Educational design and networked learning: Patterns, pattern languages and design practice. Australasian Journal of Educational Technology, 21(1), 82-101.

Goodyear, P., \& Dimitriadis, Y. (2013). In medias res : reframing design for learning. Research in Learning Technology, 21. doi:10.3402/rlt.v21i0.19909

Gorard, S., Roberts, K., \& Taylor, C. (2004). What Kind of Creature Is a Design Experiment? British Educational Research Journal, 30(4), 577-590.

Gustafson, K. L., Branch, R. M., \& Maribe, R. (2002). Survey of Instructional Development Models (4th Editio., p. 93). Syracuse, NY: ERIC Clearinghouse on Information \& Technology, Syracuse University.

Jonassen, D. H., Peck, K. L., \& Wilson, B. G. (1999). Learning With Technology: A Constructivist Perspective. New Jersey, US: Prentice Hall.

Kali, Y., Levin-Peled, R., \& Dori, Y. J. (2009). The role of design-principles in designing courses that promote collaborative learning in higher-education. Computers in Human Behavior, 25(5), 1067-1078.

Kelly, A. E. (2003). Theme Issue: The Role of Design in Educational Research. Educational Researcher, 32(1), 3-4. doi:10.3102/0013189X032001003

Koper, R. (2006). Current research in learning design. Educational Technology \& Society, 9(1), 13-22.

Lincoln, Y., Lynham, S., \& Guba, N. (2011). Paradigmatic controversies, contradictions, and emerging confluences, revisited. In N. K. Denzin \& Y. S. Lincoln (Eds.), The Sage Handbook of Qualitative Research (4th Editio., pp. 97-128). Thousand Oaks, CA: SAGE Publications.

McAleese, M. (2013). Report to the European Commission on Improving the quality of teaching and learning in Europe's higher education institutions (p. 84). Luxembourg, Publication Office of the European Union. doi:1.0.2766/42468 ISBN978-92-79-30360-9

Middleton, J., Gorard, S., Taylor, C., \& Bannan-Ritland, B. (2006). The “Compleat” Design Experiment: from soup to nuts (No. Research Paper 2006/05) (p. 39). York.

Moore, J. C. (2005). The Sloan Consortium Quality Framework And The Five Pillars (p. 9). Newburyport, MA, US.

Mor, Y. (2011). Design narratives: an intuitive scientific form for capturing design knowledge in education. In Sixth Chais Conference on Instructional Technologies Research: Learning in the Technological Era, 17 Feb 2011, (pp. 57-63). Raana, Israel: Open University, Israel.

Mor, Y., \& Craft, B. (2012). Learning design: reflections upon the current landscape. Research in Learning Technology, 20. doi:10.3402/rlt.v20i0.19196 
Mor, Y., Craft, B., \& Hernández-Leo, D. (2013). The art and science of learning design. Research in Learning Technology, 21. doi:10.3402/rlt.v21i0.22513

Mor, Y., \& Noss, R. (2008). Programming as mathematical narrative. Int. J. of Continuing Engineering Education and Life-Long Learning, 18(2), 214-233. doi:10.1504/IJCEELL.2008.017377

Mor, Y., \& Winters, N. (2007). Design approaches in technology-enhanced learning. Interactive Learning Environments, 15(1), 61-75. doi:10.1080/10494820601044236

Oliver, R., Harper, B., Wills, S., Agostinho, S., \& Hedberg, J. (2013). Describing ICT-Based Learning Designs that promote Quality Learning Outcomes. In H. Beetham \& R. Sharpe (Eds.), Rethinking Pedagogy for the Digital Age, Designing for the 21st Century (2nd Editio.). London, UK: Routledge.

Persico, D. G. (2013). Learning Design research: Where are we going? TD Tecnologie Didattiche, 21(1), 58-60.

Persico, D. G., \& Pozzi, F. (2013). Participatory Culture in Learning Design. In D. G. Persico \& V. Midoro (Eds.), Pedagogia nell'era Digitale (pp. 134-141). Genoa, Italy: Menabò.

Reiser, R. A. (2000). A History of Instructional Design and Technology: Part II: A History of Instructional Design. Educational Technology Research and Development, 49(2), 57-67.

Simon, H. A. (1969). The Sciences of the Artificial. Cambridge: The MIT press.

Vygotskij, L. (1962). Thought and Language. Cambridge: MIT Press.

Vygotskij, L. (1978). Mind in Society. The development of higher psychological processes. Oxford: Harvard University Press.

Wenger, E. (1998). Communities of Practice: Learning, Meaning, and Identity. Cambridge: Cambridge University Press. doi:10.2277/0521663636 